\section{Medical Principles}

and Practice
Benov, L. 14

Diejomaoh, M.F.E. 38

Lucas, P.W. 3
Omu, A.E. 1

Oriowo, M.A. 29

van Casteren, A. 3

\title{
Subject Index Vol. 24, Suppl. 1, 2015
}

Adipocyte-derived relaxing factor 29 Aetiology of recurrent spontaneous miscarriage 38

Anticontractile effect 29

Antiphospholipid syndrome 38

Disease management 38

Hydroxyl radical 14

Hypertension 29

Macrophages 29

Mechanical damage 3

Parental karyotype disorder 38

Perivascular adipose tissue 29
Photodynamic therapy 14

Photosensitizer 14

Porphyrin 14

Recurrent spontaneous miscarriage 38

Singlet oxygen 14

Superoxide 14

Tooth enamel 3

- fracture 3

Uterine anatomic abnormality 38

Vascular smooth muscle 29 